\title{
The Present and the Desired Organizational Culture Model of Greek Public Hospitals
}

\author{
Aspasia Goula \\ Postgraduate Program in Health and Social Care Management, Department of Business Administration, University of West \\ Attica, Egaleo, Greece \\ Email: agoula@uniwa.gr
}

How to cite this paper: Goula, A. (2020). The Present and the Desired Organizational Culture Model of Greek Public Hospitals. Journal of Human Resource and Sustainability Studies, 8, 203-218. https://doi.org/10.4236/jhrss.2020.83012

Received: June 13, 2020

Accepted: July 25, 2020

Published: July 28, 2020

Copyright (c) 2020 by author(s) and Scientific Research Publishing Inc. This work is licensed under the Creative Commons Attribution International License (CC BY 4.0).

http://creativecommons.org/licenses/by/4.0/

cc (i) Open Access

\begin{abstract}
This paper aims to record and analyze the existing organizational culture of general public hospitals and investigate the model of culture that the executives of the hospitals wish to see prevailing in the next 5-year period. The survey was conducted in twenty-six (26) general public hospitals of the region of Athens. The sample consists of 656 top and senior executives of the four departments of hospitals (medical, nursing, administrative, technical). The executives were asked to provide assessments using the Organizational Culture Assessment Instrument (OCAI), based on the Competing Values Framework of Cameron \& Quinn. The results of the survey show that the dominant organizational culture, in hospitals, can be described by the Bureaucratic Culture model (47.75\% of respondents). The model of Clan Culture $(23.76 \%)$ comes second while the Entrepreneurial-Adhocracy Culture model and the Market Culture model scored $10.02 \%$ and $14.46 \%$ respectively. The desired culture model is the Clan Culture or Participatory model (34.51\%), followed by the Market Culture model (24.47\%), model of Entrepreneurial-Adhocracy Culture model (22.49\%), and finally the Bureaucratic Culture model (19.03\%). In the existing situation, general public hospitals are characterized by internal orientation, observance of rules and processes as well as focus on control hierarchy, predictability and stability. The model of Entrepreneurial-Adhocracy Culture and the model of Market Culture, which both focus on the exterior macro-environment and growth for the hospital, record small percentages. As far as the future is concerned, hospital executives would like to see a change from the Bureaucratic Culture model of organization, to the direction of Participatory model, which will include elements of flexibility, creativity, dynamism and competitiveness that are inherent in the other two models (Market and Entrepreneurial-Adhocracy). The focus remains on the internal environment of hospitals but at the same time there is evidence of the wish to look into the external environment of hospital as well.
\end{abstract}




\section{Keywords}

Organizational Culture, Models of Culture, Organizational Climate, Public Hospitals, Organizational Change

\section{Introduction}

The development of organizational culture, as an autonomous field of study, began the decades 1940 and 1950, from the science of anthropology, followed the science of sociology and social psychology (Carney, 2006). After that, theorists of organizational and administrative science, acquired special study interest and they attempted to determinate and include in their analysis the organizations as cultures (Chytiris, 2001; Zavlanos, 2002).

The theoretical frame of organizational culture results from the combination of organizational psychology, social psychology and social anthropology (Scott et al., 2003a). The definitions that were recorded, the last 30 years, for the sense of organizational culture, vary, depending on the scientific sector that the scholar belongs. The academic community agrees that, the culture includes or visible organizational structures and processes, or acceptable values, or deeper and unprincipled convictions, perceptions, thoughts, sentiments and behaviors.

Ouchi and Wilkins (1985) characterize the culture as the philosophy that guides an organization's policy towards employees or customers. Cooke and Rousseau (1988) define it as a set of common knowledge of a social group that is acquired through social learning and social process of its members while Argyris and Schon (1978) believe that are the employee's common intellectual arrests that define each person's position in the group.

Jones (2010) considers that they are the common values and rules that control the actions and reactions of the organization members with each other and with suppliers, customers, outsiders while other researchers (Kotter, 2001; Van den Beng \& Wilderom, 2001) point out that they are the rules of conduct or the specific ways managing organizational functions that have been developed over long periods of time taught or imposed on members.

Schein (2004) states that culture is a social control mechanism and may be the basis for manipulating the members of the organization in response, thinking and feeling, or as Cameron (2004) mentions, is a socially constructed property of organizations that served as a mechanism for connecting the organization's members.

Suitable for the organization culture has proven to be a source of competitive advantage (Preffer \& O'Reilly 2000; Platonova et al., 2006) and is considered as a critical variable considering the competitiveness, the efficiency, the profitability and the long-term success (Bourantas, 2002).

Studies have also described a dynamic link between organizational culture and the financial performance of the organization. Miroshnik (2002), demonstrated that there is a strong relationship between the development of an organization 
and the appropriate and uniform culture while Denison and Mishra (1995), and Ogbonna and Harris (2000), emphasize that if an organization has a strong culture with built-in values and behaviors, is driven to a high level of operation.

The academic literature also recognizes the impact of organizational culture on the productivity of organizations and on the quality of services provided. Deal and Kennedy (1999) report that appropriate administrative practices lead to positive behavior of employees and thus to productivity improvements.

Manley (2000), Mathew (2007) and Barney (1986), emphasize that organizational culture influences the effectiveness of the organization because it can give it a competitive advantage, improve the way the organizational structure works and increase the incentives of employees to achieve the organization's interests. They point out that organizational culture is the determining factor that encourages innovation, flexibility and adaptability of the organization.

In the environment of health systems, organizational culture has been linked to various elements that contribute to the quality of services such as satisfaction from nursing care and patient safety; the availability of members to improve the efficiency and effectiveness of the organization and the satisfaction of members from meeting their material and social needs (Scott et al., 2003b).

Researches on the organizational culture and the dimensions that affect a health care unit have shown that culture shapes organizational function and efficiency (Davies et al., 2007), quality assurance (Shortell et al., 1995), quality of care for patients (Rondeau \& Wagar, 1998), efficiency and satisfaction of employees (Goodman et al., 2001; Gifford et al., 2002), patient satisfaction (Meterko et al., 2004), cooperation and relationships between the internal and external clients of the organization as well as the reputation of the health unit (Mannion et al., 2005).

In the UK Health System reform, management of organizational culture was considered as an indispensable administrative tool, and special programs of organizational change in the healthcare culture were implemented as part of improving the operation of hospitals (Mannion et al., 2007). In Ireland and in the United States, organizational culture has been the key to improving quality in health (Badham et al., 2006).

In order to describe the types of organizational culture that exist in organizations, several scientific approaches have been made. Researchers in the first stage of study have observed many common features of organizational culture.

Common features categorized them into types of culture. Their goal was to create useful tools to understand better the characteristics of the organization. A better understanding contributes both to the formation of an effective management of the organization in the current situation as well as to an effective management of an upcoming change in the organization's culture. These theoretical approaches also include the Cameron and Quinn Competitive Framework.

\section{Materials and Methods}

There are 30 public hospitals in the Attica Basin. The survey was conducted in twenty (26) of them. A selection criterion, for the majority of them, was the key 
position they hold in the hospital system of the Basin. The survey has chosen those hospitals that receive a large amount of patients on a daily basis. Hospitals in Greece have four services: Medical, Nursing, Administrative and Technical Service. Population of the survey was the top and senior management of these four (4) hospital services. The choice of research at the above-mentioned hierarchical level was based on corresponding international surveys that argue that the particular reference population knows in-depth the organizational characteristics of the hospitals and can therefore define specific aspects of the organizational culture (Platonova et al., 2006; Davies et al., 2007; Mannion et al., 2005; Philippidou et al., 2004; Gerowitz, 1998; Scott et al., 2003c).

As a sampling method, stratified random sampling was selected. The survey lasted 10 months (1/6/2018 to 30/4/2019). 800 questionnaires were distributed and 656 (82\% response rate) were returned, of which 235 (35.8\%) belonged to the Medical Service, 225 to the Nursing Service (34.3\%), 169 to the Administrative Service (25.8\%) and 27 to the Technical Service (4.13\%). The questionnaires were supplemented by the sample self-referral method.

The Organizational Culture Assessment Instrument (OCAI) of Cameron and Quinn, based on the Competitive Values Framework, was used to measure the organizational culture.

The Competitive Values Framework theory attempts to identify the factors that affect the effectiveness of the organization, recognizes that organizations are dynamic and complex, driven at the same time in competitive directions, and the leader of the organization must have behavioral leadership complexity in this paradoxical business environment (Lawrence et al., 2009).

Competitive Values Framework Theory is considered as a grid that can be divided into four models of culture (clan model, entrepreneurial-adhocracy model, market culture model, bureaucratic - hierarchy model) and in two dimensions (focus on the internal environment and focus on the external environment). Each model represents a theory, a philosophy, a look at the way an organization works and is directly linked to a system of values. All models are inherently different to each organization (Cameron \& Quinn, 2006).

Based on the theory, Cameron and Quinn developed the Organizational Culture Assessment Instrument. O'Neill and Quinn (1993) argue that the tool reflects the complexity faced by organization workers every day while Kwan and Walker (2004) see it as a powerful methodological method for organizational culture research.

According to Kalliath et al., (1999), the tool has been applied to different organizations in order to identify the organizational culture, management style and its effect on the effectiveness of the organization, the exploration of the relationship between culture and development of organisms, the study of the organizational life cycle, the correlation between organizational culture and strategy, the efficiency of information management systems, and organizational communication.

With regard to its use in hospital settings, Mannion et al., (2005) after syste- 
matic monitoring, concluded that the tool is suitable for the study and measurement of organizational culture in hospitals because, unlike most methodological tools, it has a theoretical basis, it has used extensively with credible results, has a strong surface validity and, finally, produces a typology of culture which is not only a quantitative tool but also assists in qualitative analysis and data interpretation.

This tool explores six (6) dimensions of organizational culture: 1) The dominant characteristics of the organization, 2) The style of leadership, 3) The management of human resources, 4) The dominant element that ensures unity within the organization, 5) The development strategy, and 6) The criteria of success it sets the agency for the future (Cameron \& Quinn, 2006).

Reliable and authoritative studies have demonstrated that these six dimensions can provide a comprehensive picture of organizational culture. For each dimension, four (4) options are given. These alternative options are the culture models supported in the theory of Competing Values Framework. Members are asked to evaluate these alternatives (Cameron \& Quinn, 2006).

Specifically, the English version of the questionnaire was translated into Greek language and back-translated into English for checking. The forward translators consisted of two independent native-speaking translators. The translators independently translated the original version of the Organizational Culture Assessment Instrument into Greek language. Both translators were familiar with the tool. Both translators synthesized their forward translation, where poor wording choices were identified and resolved in order to ensure semantic and conceptual equivalence. The translated questionnaire was discussed with two (2) experts in this field, and minor changes were then made to ensure that the wording was appropriate for the local context. The developed questionnaire was pilot tested on a convenience sample of 50 health professionals and no major problems were observed.

The data were checked for completeness and correctness. To analyze these, the use of the Social Science Statistical Package (SPSS 21) was chosen. A one way multivariate analysis of variance (MANOVA) was conducted to test whether there is significant mean difference between the four models of the hospitals organizational culture. Prior to conducting the MANOVA, the box plots of the depended variables were constructed to check the multivariate normality assumption. Cronbach's alpha internal consistency coefficient was calculated to test the reliability of the instrument. The reliability instrument results were as follows: Clan Model: 0.819, Entrepreneurial-Adhocracy Model: 0.687, Market Culture Model: 0.664, Bureaucratic-Hierarchy Model: 0.755

The simplified form of the MTMM was used to check the construct validity of the instrument through which convergent and discriminate validity were tested.

A Spearman's correlation was run to assess the relationship between variables of the same model $(p<0.0001)$. It was found that there was a moderate to strong correlation between them which was statistically significant (Table 1). 


\section{Results}

\subsection{Socio-Demographic Characteristics}

Of the respondents (656 people), $278(42.4 \%)$ are men and $378(57.6 \%)$ are women. $57.3 \%$ belongs to the top management and the rest $(42.7 \%)$ belongs to senior management. The majority of the sample (45.1\%) belongs to the age group 45 - 54. 51.8\% of the sample has a degree from university, $19.6 \%$ has a postgraduate degree and $28.7 \%$ has a $\mathrm{PhD}$ degree (mainly doctors). The majority of the sample (58.0\%) has work experience in a public hospital of $\geq 25$ years, while $42.0 \%$ have a work experience of $<25$ years (Table 2 ).

Table 1. Variables correlations of the same model (Spearman Correlation).

\begin{tabular}{cccc}
\hline \multicolumn{2}{c}{ Present Situation } & \multicolumn{3}{c}{ Desired Situation } \\
\hline Clan Model & $0.327-0.787$ & Clan Model & $0.311-0.535$ \\
Entrepreneurial-Adhocracy Model & $0.431-0.636$ & Entrepreneurial-Adhocracy Model & $0.2-0.45$ \\
Market Culture Model & $0.345-0.617$ & Market Culture Model & $0.23-0.52$ \\
Bureaucratic-Hierarchy Model & $0.354-0.695$ & Bureaucratic-Hierarchy Model & $0.2-0.63$ \\
\hline
\end{tabular}

Table 2. Frequency distribution by socio-demographic data.

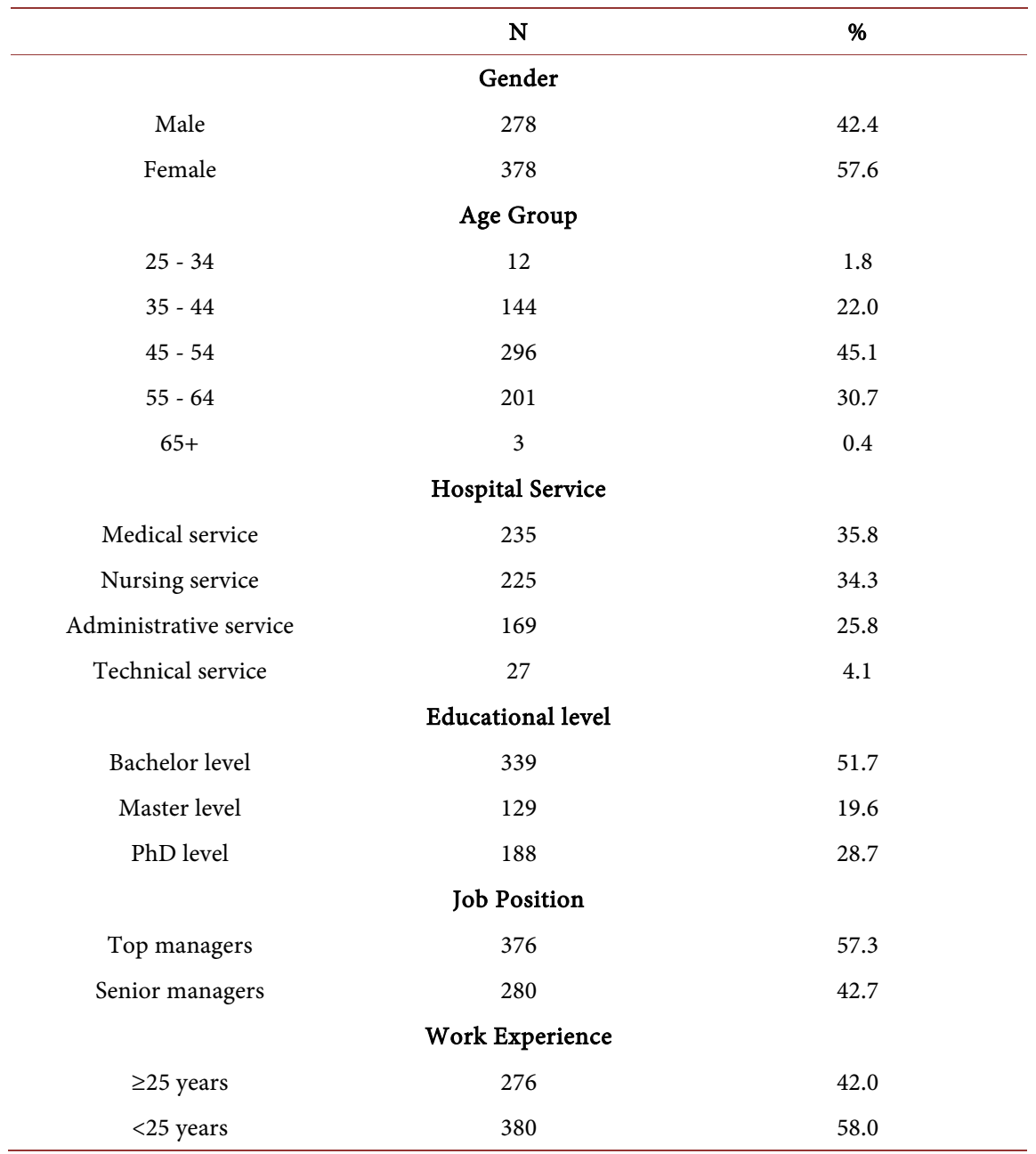




\subsection{Analysis of the Dimensions of the Organizational Culture Assessment Instrument}

\section{1) The hospital overall picture of organizational culture}

Of a total of 656 hospital managers, $47.75 \%$ believe that the organizational culture that dominates into the organization is the bureaucratic model ( $p$-value $<0.01$ ). The clan model follows at $26.67 \%$ while the entrepreneurial-adhocracy culture model and the market culture model were $10.02 \%$ and $14.46 \%$, respectively. In the desired situation, the model of organizational culture that the executives want is the clan $(34.51 \%)$ ( $p$-value $<0.01)$ follows the market culture model (24.47\%), the entrepreneurial-adhocracy culture model $(22.49 \%)$ and the bureaucratic model with only $19.03 \%$. The difference between the last model in the present and the desired state is about 29 percentage points (Picture 1, Table 3).

2) Culture models in present \& desired situation per dimension of the tool

Table 3 shows the score recorded per tool dimension both in the present and the desired (after 5 years) organizational situation.

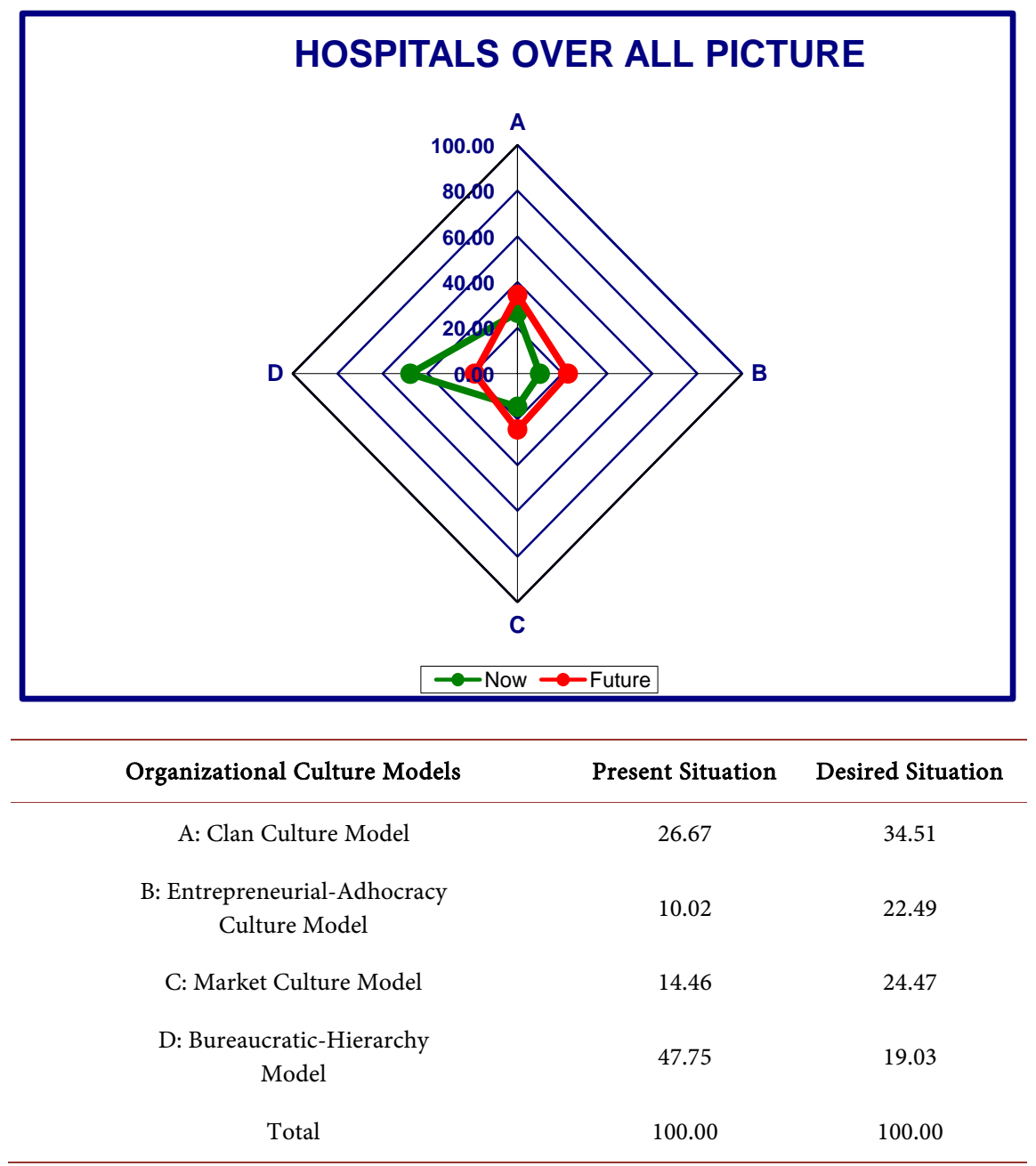

Picture 1. The overall organizational culture of 26 general public hospitals. 
Table 3. Rating by tool dimension.

\begin{tabular}{|c|c|c|}
\hline TOOL DIMENSION & PRESENT SITUATION & DESIRED SITUATION \\
\hline \multirow{8}{*}{$\begin{array}{l}\text { 1) HOSPITALS } \\
\text { DOMINANT } \\
\text { CHARACTERISTS }\end{array}$} & Bureaucratic-Hierarchy & Clan Culture Model: 38.02\% \\
\hline & Model: $\mathbf{3 7 . 8 2} \%$ & Entrepreneurial-Adhocracy Culture \\
\hline & Clan Culture Model: 32.85\% & Model: $20.10 \%$ \\
\hline & Entrepreneurial-Adhocracy Culture & Market Culture Model: $28.35 \%$ \\
\hline & Model: $10.59 \%$ & Bureaucratic-Hierarchy Model: \\
\hline & Market Culture Model: 12.43\% & $13.75 \%$ \\
\hline & Bureaucratic-Hierarchy Model: & Clan Culture Model: $36.68 \%$ \\
\hline & $46.64 \%$ & Entrepreneurial-Adhocracy Culture \\
\hline 2) ORGANISATIONS & Clan Culture Model: $25.35 \%$ & Model: $18.94 \%$ \\
\hline \multirow[t]{4}{*}{ LEADERSHIP } & Entrepreneurial-Adhocracy Culture & Market Culture Model: 19.69\% \\
\hline & Model: $11.38 \%$ & Bureaucratic-Hierarchy Model: \\
\hline & Market Culture Model: 16.61\% & $24.27 \%$ \\
\hline & Bureaucratic-Hierarchy Model: & Clan Culture Model: $36.80 \%$ \\
\hline \multirow{7}{*}{$\begin{array}{l}\text { 3) HUMAN } \\
\text { RESOURSES } \\
\text { MANAGEMENT }\end{array}$} & $51.97 \%$ & Entrepreneurial-Adhocracy Culture \\
\hline & Clan Culture Model: 22.59\% & Model: $22.10 \%$ \\
\hline & Entrepreneurial-Adhocracy Culture & Market Culture Model: 25.07\% \\
\hline & Model: $9.09 \%$ & Bureaucratic-Hierarchy Model: \\
\hline & Market Culture Model: 15.81\% & $16.84 \%$ \\
\hline & Bureaucratic-Hierarchy Model: & Clan Culture Model: $27.25 \%$ \\
\hline & $52.89 \%$ & Entrepreneurial-Adhocracy Culture \\
\hline 4) ORGANISATIONS & Clan Culture Model: 21.13\% & Model: $26.07 \%$ \\
\hline \multirow[t]{5}{*}{ GLUE } & Entrepreneurial-Adhocracy Culture & Market Culture Model: $27.78 \%$ \\
\hline & Model: $10.15 \%$ & Bureaucratic-Hierarchy Model: \\
\hline & Market Culture Model: 15.81\% & $19.53 \%$ \\
\hline & Bureaucratic-Hierarchy Model: & Clan Culture Model: $31.18 \%$ \\
\hline & $53.55 \%$ & Entrepreneurial-Adhocracy Culture \\
\hline 5) STRATEGIC & Clan Culture Model: 24.88\% & Model: $24.86 \%$ \\
\hline \multirow[t]{5}{*}{ EMPHASES } & Entrepreneurial-Adhocracy Culture & Market Culture Model: 26.97\% \\
\hline & Model: $8.90 \%$ & Bureaucratic-Hierarchy Model: \\
\hline & Market Culture Model: 13.05\% & $17.10 \%$ \\
\hline & Bureaucratic-Hierarchy Model: & Clan Culture Model: $36.64 \%$ \\
\hline & $43.64 \%$ & Entrepreneurial-Adhocracy Culture \\
\hline 6) CRITERIA OF & Clan Culture Model: $33.22 \%$ & Model: $22.89 \%$ \\
\hline \multirow[t]{3}{*}{ SUCCESS } & Entrepreneurial-Adhocracy Culture & Market Culture Model: $17.36 \%$ \\
\hline & Model: $10.02 \%$ & Bureaucratic-Hierarchy Model: \\
\hline & Market Culture Model: $13.10 \%$ & $22.69 \%$ \\
\hline
\end{tabular}

The "Hospital Dominant Characteristics" dimension reflects the core values, attitudes and processes governing in an organization. In the current situation, control, regulations and generally the activities of staff are determined by bureaucratic procedures. The focus is on the internal environment of the organization. The model of the entrepreneurial-adhocracy culture, characterized by initiative and dynamism, occupies a small percentage (10.59\%). The same is happening of the market culture model which characterized by competition and market dominance (12.43\%).

In the desired situation, the working climate desired by executives is the model of clan culture. They want to support their participation in decision-making, to have the opportunity for initiatives, to feel that they belong to a large family with common vision and goals. Impressive are also the percentages of market and entrepreneurial-adhocracy culture models. It thus appears that the majority 
of the hospital staff (48.45\%) wants a focus on the hospital's external environment. They want to be competitive, dynamic, take innovative initiatives and emphasize the efficiency and effectiveness of their work.

The "Organization Leadership" dimension refers to the style of behavior and the way in which the members of the organization exercise power. The concept of hospital leadership includes both the hospital administrators and the directors of the four separate departments. In the current survey, $46.64 \%$ of hospital executives, for the present situation, state that hospital leadership is mainly interested in the smooth flow of bureaucratic processes, coordination and short-term organization of these. This percentage reflects views mainly from executives from the medical, administrative and technical service. A percentage (24.18\%), mainly from nursing staff, believes that leadership guides, protects and facilitates their work. There is, therefore, a dimension to the issue of leadership depending on the service that the executives belong to.

On the contrary, in the desired situation, executives, from all services, seek (36.68\%) that leadership that will consider the existing partner, develop them and empower them in the realization of their work and finally guide them with his/her behavior in the development of team spirit and team collaboration. In addition, $18.94 \%, 19.69 \%$ and $24.27 \%$ of the other leadership models indicate the need for executives of a leadership with multifaceted skills and abilities. A leadership that, while coordinating and organizing the day-to-day operations and processes of the hospital, will at the same time not hesitate to contribute to its decisions, to competitiveness, to emphasize the results of the work, to innovate, to take risks and all this under the perspective of participatory management.

The "Human Resources Management" dimension reflects the way in which human resources are organized and managed in hospitals. In the current situation, the executives claim (51.97\%) that they are characterized by a sense of security and permanence, monotony and stability in labor relations. Principles inherent in the bureaucratic model, in services like nursing or medicine, where there is a daily contact with the "client-patient" of the hospital, they develop in parallel with the formal and informal forms of human resources management. This explains the high scores in clan culture model (22.59\%) and in market culture model (15.81\%).

In the future, executives believe that employees' management must be characterized by teamwork, consensus, participation, innovation, individual initiative, freedom, originality and high demands from employees with an emphasis on production and attainment of goals.

The "Organization Glue" is considered to be the mechanism that acts as a link and connects all the members of the organization. In the current situation, the majority of executives believe that the predominant element in hospitals is the application of formal procedures and rules and the maintenance of process flow. In some cases (21.13\%) recorded elements of clan model, such as mutual trust, loyalty, and commitment to the organization, appear. In the present situation the focus is on internal of the organization. 
Instead, in the future, executives want the dominant component of the organization to focus on the external environment, focusing on competitiveness, achieving the goals and success of the hospital, as well as emphasizing the innovation and development of hospital departments. At the same time, they believe that commitment and loyalty to the organization is an important element of its coherence.

The "Strategy Emphases" is the organization's excellent integration into its environment to ensure survival, growth and prosperity. In the current situation, hospital executives believe that the hospital's strategy focuses on the permanence and stability of the conditions. For the hospital today, it is important to control and maintain the procedures.

In the desired situation, $31.18 \%$, stresses that more emphasis should be placed on the development of human resources with a high degree of employee participation in decision-making while $51.83 \%$ believe that the hospital's strategy should be oriented to the external environment to raise new resources and new opportunities through competitive actions and health gains.

The "Criteria Success" dimension records those factors that lead to success. In the current situation, executives believe that success in the hospital is defined as low operating costs, good planning and reliability in service delivery. At the same time, they consider that employee commitment and interest in patients is a factor in achieving hospital success. Consequently, the focus, in this dimension of organizational culture, lies within the organization's internal environment.

In the future, hospital executives emphasize that success criteria should continue to be human resource development, teamwork and commitment, low operating costs, service reliability and good planning, but at the same time believe that innovative services and competitiveness should be defined as new success criteria. Thus, the tendency to focus on the external environment and this dimension of organizational culture is observed.

Regarding the size (large-medium) of the hospital, it affects the existing ( $p$-value $=0.036<0.05)$ but not the desired culture model. In the current situation, executives of both large and medium-sized hospitals believe that the bureaucratic model is in place. The only difference, in medium-sized hospitals, appears in the human resource model that has a more positive attitude towards that model ( $p$-value $=0.025$ ). Therefore, it is confirmed that the smaller the size of an organism, the more easily the atypical structures and relationships between its members are created. This observation agrees with research results, which suggest that small and medium-sized organizations have a more open climate, while the larger the organization, the greater the degree of bureaucracy with more control and coordination and the dominance of the closed climate (Philippidou et al., 2004). In the desired situation there is a corresponding agreement (clan culture model) regardless of the size of the hospital.

The previous years of service $(p$-value $=0.048)$ and the gender $(p$-value $=$ 0.078 ) of the hospital staff do not affect their views on the present and the desir- 
able organizational culture. Research has identified as an existing the hierarchical-bureaucratic model and desirable the clan, regardless of years of professional experience or gender.

The hierarchical position $(p$-value $=0.002<0.05)$ seems to influence differently the perceptions of executives about the existing organizational culture model. While all hierarchical positions consider the bureaucratic model of culture to prevail, the deputy directors consider the bureaucratic model to be less applicable and give a high percentage to the market model. In the desired situation, the model of human resources prevails over the others as a whole in all hierarchical positions.

The service ( $p$-value $=0.0005<0.05)$ affects the power of the models only in the current state. The bureaucratic model is more powerful in the technical, medical and administrative departments. In the nursing service, while prevailing over the other three, the clan model and the entrepreneurial-adhocracy are nevertheless receiving a higher degree of power than the other three services. Therefore, the nursing service has a more patient-center character. The day-to-day contact of nurses with the patient to treat the illness and the immediate therapeutic efficacy to relieve them highlights the entrepreneurial-adhocracy model as also powerful.

\section{Discussion}

The main purpose of this article is to record and analyze the existing organizational culture of general public hospitals as well as to investigate the culture model that executives want to govern the organization over the next 5 years.

According to the survey, public hospitals have an internal orientation, adherence to rules and procedures, focus on control, hierarchy, predictability and stability. The market and the entrepreneurial-adhocracy culture model, focus on the external long-term environment and the development of the hospital, record small percentages. Cameron and Quinn (2006) argue that the higher the percentage in a culture model, the stronger this culture is in the organization. In this research, the range of difference between the bureaucratic model and the clan model, recorded as the second option, ranges around 21 units, thus demonstrating that the current culture of public hospitals is that of a strong culture. The above result is in contradiction with a similar survey showing weak culture in Greek public hospitals (Kastanioti et al., 2011).

The desirable model of organization, according to executive opinion, is that of clan or participatory management. The market and the entrepreneurial-adhocracy culture models follow with a small difference between them. The bureaucratic model occupies the last place in executive choices. The difference, in the present with the desired organizational culture, is 29 percentage points, which demonstrates a strong and clear desire for change. According to Cameron \& Quinn (2006), if the range of difference between the present and the desired organizational culture exceeds 10 percentage points, it is also suggested that immediate measures have to be taken to promote the change of culture.

This study marks the desire to change the bureaucratic model of organization 
towards the model of participatory management, which will contain elements of flexibility, creativity, dynamism and competitiveness, elements from the other two models (entrepreneurial-adhocracy and market). Although the focus remains within the hospitals, it is also on the outside environment of the hospital. From the foregoing, the desire to co-exist with two or more forms of culture is concluded. The desired goal focuses on growth and expansion, but at the same time focuses on the desire to apply formal rules of communication between the members of the organization and control of information.

Consequently, in the present study, the theory of the Competitive Framework or the Quinn \& Cameron paradoxical theory, this argues that the organisms are simultaneously driven in competing directions and contain different characteristics, is widely recognized. Organizations are clear and dynamic and complex and require leaders to respond to different roles and situations. This behavioral complexity often requires different competitive behaviors. Leadership can, on the one hand, manage rationally the day-to-day running of organizations based on the resources of the organization; on the other hand strive for a balance between the competitive expectations inherent in the organization.

Under this approach, public hospital leaders should plan long-term and short-term, be rigid and flexible, decentralized and centralized, identify goals with available resources and be interested in both employees' satisfaction and patient needs.

The survey did not record the existence of subculture in the public hospitals under consideration. A subculture is defined as a group of people with particularly common characteristics regardless of the general culture of the organization. Culture, particularly in the current situation, could be described as a "unified culture", a culture with a broad consciousness of values, attitudes and behaviors within the organization (Martin, 1992). All four hospital addresses are geared to the bureaucratic model of culture. Nonetheless, nursing services in hospitals apply, even atypical, at primary level, values of the participatory model and the entrepreneurial-adhocracy model, to serve the patients.

Regarding the six (6) dimensions of the tool in the present state, the bureaucratic model of culture prevails over the others. Consequently, in the present situation, a $100 \%$ agreement was recorded in all six dimensions of the tool. In the desired situation, $83 \%$ agreement was recorded between the six dimensions. The "organization glue" dimension differs from the others, suggesting as the first desired option the market culture model. The focus on this dimension focuses on the external environment of the hospital with emphasis on competitiveness, achievement of objectives, innovation and the development of departments. More generally, analyzing the results of research, in the desired situation per dimension, it is found that the hospital executives:

They want the dominant characteristic of the hospital, namely the climate that will prevail, to be support decision-making participation, opportunities for initiatives, the ability to be competitive and dynamic and to take innovative decisions with emphasis on efficiency and efficiency of their work. 
They are looking for a leadership that, while coordinating and organizing the day-to-day operations and processes of the hospital, at the same time will not hesitate to contribute to its competitiveness decisions, to focus on the results of its work, to innovate, to take risks, the in light of perspective of participatory management. They essentially want a charismatic leadership with a focus on the hospital's internal and external environment.

They want the human resources management to be characterized by teamwork, consensus, participation, innovation, individual initiative, freedom, originality with emphasis on production and achievement of goals, with respect to the individual value of each member of the hospital. They believe that the dominant element of the hospital, what really motivates them, must be commitment and loyalty to the organization as well as the emphasis on innovation and competitiveness.

They believe that the hospital's strategy should be geared to the external environment in order to draw on new resources and new opportunities through competitive actions and health gain through the development and participation of human resources.

They consider future success criteria, human resources development, team membership and commitment, low operating costs, service reliability and good planning.

\section{Conclusion}

The main and essential conclusion of the research is the discovery of the universal desire to change organizational culture on the part of top and senior executives. The rigid bureaucratic model, with its rigidity, the fear of modernizing initiatives and reforms and the limited use of human resources, is a key causal factor in curbing the satisfaction of the human potential of the hospital system, that is, it is the cause of a developmental limitation of its main factor production process. The solution is to change the bureaucratic model of culture into participatory model. The implementation of the participatory culture model will motivate hospitals' members to participate effectively in the actions of their organizations. International research has shown that the participatory culture model has positive effects on patient safety, on efficiency and effectiveness and on employees' satisfaction.

\section{Limitations}

There are some limitations with this study that need to be recognized. The results of the survey refer only to the largest urban center of the country, so the findings can only be limited to these public hospitals and may not represent the organizational culture model of all public hospitals in the country. Future research could be carried out in other geographical districts in order to compare the public hospitals culture. Additionally, the survey was carried out on top and senior hospital executives. It would be very interesting to record the organiza- 
tional culture of other members of the hospitals and to investigate differences.

\section{Acknowledgements}

This study has been done within the framework of the Postgraduate Health and Social Care Management Programme of the University of West Attica.

\section{Conflicts of Interest}

The author declares no conflicts of interest regarding the publication of this paper.

\section{References}

Argyris, C., \& Schon, D. (1978). Organizational Learning: A Theory of Action Perspective. Reading, MA: Addison-Wesley.

Badham, J., Wall, D., Sinfield, M., \& Lancaster, J. (2006). The Essence of Care in Clinical Governance. Clinical Governance: An International Journal, 11, 22-29. https://doi.org/10.1108/14777270610646994

Barney, J. (1986). Organizational Culture: Can It Be a Source of Sustained Competitive Advantage? The Academic Management Review, 11, 656-665. https://doi.org/10.5465/amr.1986.4306261

Bourantas, D. (2002). Management. Athens: Benos.

Cameron, K., \& Quinn, R. (2006). Diagnosing and Changing Organizational Culture. San Francisco, CA: Jossey-Bass.

Cameron, K. A. (2004). Process for Changing Organizational Culture. In The Handbook of Organizational Development (pp. 429-445). London: Michael Driver.

Carney, M. (2006). Understanding Organizational Culture: The Key to Successful Middle Manager Strategic Involvement in Health Care Delivery. Journal of Nursing Management, 14, 23-33. https://doi.org/10.1111/j.1365-2934.2005.00592.x

Chytiris, L. (2001). Organizational Behaviour. Athens: Interbooks.

Cooke, R. A., \& Rousseau, D. M. (1988). Behavioral Norms and Expectations: A Quantitative Approach to the Assessment of Organizational Culture. Group \& Organization Management, 13, 245-273. https://doi.org/10.1177/105960118801300302

Davies, H., Mannion, R., Jacobs, R., Powell, M., \& Marshall, M. (2007). Exploring the Relationship between Senior Management Team Culture and Hospital Performance. Medical Care Research and Review, 64, 46-65. https://doi.org/10.1177/1077558706296240

Deal, T. E., \& Kennedy, A. A. (1999). The New Corporate Cultures. Reading, MA: Perseus Books.

Denison, D., \& Mishra, A. (1995). Toward a Theory of Organizational Culture and Effectiveness. Organizational Science, 6, 204-223. https://www.jstor.org/stable/2635122 https://doi.org/10.1287/orsc.6.2.204

Gerowitz, M. B. (1998). Do TQM Interventions Change Management Culture? Findings and Implications. Quality Management in Health Care, 6, 1-11. https://doi.org/10.1097/00019514-199806030-00001

Gifford, B. D., Zammuto, R. F., \& Goodman, E. A. (2002). The Relationship between Hospital Unit Culture and Nurses' Quality of Work Life. Health Care Management, 47, 13-25. https://doi.org/10.1097/00115514-200201000-00005 
Goodman, E. A., Zammuto, R. F., \& Gifford, B. D. (2001). The Competing Values Framework: Understanding the Impact of Organizational Culture on the Quality of Work Life. Organizational Development Journal, 19, 58-68.

https://psycnet.apa.org/record/2003-03433-004

Jones, G. (2010). Organizational Theory, Design, and Change (6th ed.). Pearson, NJ: Pearson Prentice Hall.

Kalliath, T., Bluedorm, A., \& Gillespie, D. (1999). A Confirmatory Factor Analysis of the Competing Values Instrument. Educational and Psychological Measurement, 59, 143-158. https://doi.org/10.1177/0013164499591010

Kastanioti, A., Siourouni, E., Mauridoglou, G., \& Polizos, N. (2011). Comparative Assessment of Health Units Organizational Culture. Archives of Hellenic Medicine, 28, 70-78.

Kotter, J. (2001). Leader in Changes. Athens: Kritiki.

Kwan, P., \& Walker, A. (2004). Validating the Competing Values Model as a Representation of Organizational Culture through Inter-Institutional Comparisons. Organizational Analysis, 12, 21-39. https://doi.org/10.1108/eb028984

Lawrence, K. A., Lenk, P., \& Quinn, R. (2009). Behavioral Complexity in leadership: The Psychometric Properties of a New Instrument to Measure Behavioral Repertoire. The Leadership Quarterly, 20, 87-102. https://doi.org/10.1016/j.leaqua.2009.01.014

Manley, K. (2000). Organizational Culture and Consultant Nurse Outcomes. Nursing Standard, 14, 34-38. https://doi.org/10.7748/ns2000.05.14.36.34.c2840

Mannion, R., Davies, H., \& Marshall, M. (2005). Cultures for Performance in Health Care. London: Open University Press, McGraw-Hill Education.

Mannion, R., Davies, H., \& Marshall, M. (2007). Cultures for Performance in Health Care: Evidence on the Relationships between Organizational Culture and Performance in the NHS. York: The University of York.

Martin, J. (1992). Culture in Organizations: Three Perspectives. New York: Oxford University Press.

Mathew, J. (2007). The Relationship of Organizational Culture with Productivity and Quality. Employee Relations, 29, 677-695. https://doi.org/10.1108/01425450710826140

Meterko, M., Mohr, D. C., \& Young, G. J. (2004). Teamwork Culture and Patient Satisfaction in Hospitals. Medical Care, 42, 492-498. https://doi.org/10.1097/01.mlr.0000124389.58422.b2

Miroshnik, V. (2002). Culture and International Management: A Review. Journal of Management Development, 21, 521-544. https://doi.org/10.1108/02621710210434647

O’Neill, R., \& Quinn, R. (1993). Applications of the Competing Values Framework. Journal of Human Resource Management, 32, 1-7. https://doi.org/10.1002/hrm.3930320101

Ogbonna, E., \& Harris, L. (2000). Leadership Style, Organizational Culture and Performance: Empirical Evidence from UK Companies. International Journal of Human Resource Management, 11, 766-788. https://doi.org/10.1080/09585190050075114

Ouchi, W., \& Wilkins, A. (1985). Organizational Culture. Annual Review of Sociology, 11, 457-483. https://www.jstor.org/stable/2083303

https://doi.org/10.1146/annurev.so.11.080185.002325

Philippidou, S., Prastacos, G., \& Soberquist, E. (2004). Towards New Public Management in Greek Public Organizations: Leadership vs. Management, and the Path to Implementation. Public Organization Review: A Global Journal, 4, 317-337.

https://doi.org/10.1007/s11115-004-4600-7 
Platonova, E. A., Hernandez, R. S., Shewchuk, R. M., \& Leddy, K. M. (2006). Study of the Relationship between Organizational Culture and Organizational Outcomes Using Hierarchical Linear Modeling Methodology. Quality Management in Health Care, 15, 200-209. https://doi.org/10.1097/00019514-200607000-00009

Preffer, J., \& O’Reilly, C. (2000). Hidden Value. Boston, MA: Harvard Business School.

Rondeau, V., \& Wagar, T. (1998). Hospital Chief Executive Officer Perceptions of Organizational Culture and Performance. Hospital Topics Journal, 76, 14-22. https://doi.org/10.1080/00185869809596494

Schein, E. (2004). Organizational Culture and Leadership (3rd ed.). San Francisco, CA: Jossey-Bass.

Scott, K., Mannion, R., Davies, H., \& Marsall, M. (2003a). The Quantitative Measurement of Organizational Culture Care: A Review of the Available Instruments. Health Services Research, 38, 923-945. https://doi.org/10.1111/1475-6773.00154

Scott, K., Mannion, R., \& Marsall, M. (2003c). Does Organizational Culture Influence Health Care Performance? A Review of the Evidence. Journal of Health Services Research \& Policy, 8, 105-117. https://doi.org/10.1258/135581903321466085

Scott, K., Mannion, R., Davies, H., \& Marsall, M. (2003b). Healthcare Performance and Organizational Culture. Oxford: Radcliffe Medical Press.

Shortell, S. M., O’Brien, J. L., Carman, J. M., Foster, R. W., Hughes, E. F., \& Boerstler O'Connor, E. J. (1995). Assessing the Impact of Continuous Quality Improvement/Total Quality Management: Concept versus Implementation. Health Service Research, 30, 377-401.

Van den Beng, P., \& Wilderom, C. (2001). Defining, Measuring, and Comparing Organizational Cultures. Journal of Applied Psychology: An International Review, 53, 570-582. https://doi.org/10.1111/j.1464-0597.2004.00189.x

Zavlanos, M. (2002). Organizational Behaviour. Athens: Stamoulis. 